\title{
Caýda de príncipes: la Vulgata castellana del De Casibus Virorum Illustrium de Boccaccio
}

\author{
José Blanco Jiménez* \\ Universidad Santo Tomás, Chile
}

\begin{abstract}
Resumen
Sabemos casi todo respecto a cómo se llevó a efecto, en el siglo $\mathrm{XV}$, la traducción castellana del De casibus virorum illustrium de Giovanni Boccaccio y acerca de los códices que la contienen. Falta, sin embargo, un estudio referente a la "vulgata" de dicho texto, establecida por la edición de Sevilla (1495), que fue replicada después en Toledo (1511) y Alcalá de Henares (1552). Las variantes y la disposición de los capítulos podrían ser fruto de una manipulación de los curadores o de la existencia de un segundo arquetipo.
\end{abstract}

Palabras clave: Boccaccio, Caýda de príncipes, literatura latina medieval, literatura castellana renacentista

\section{CAÝda de PRÍNCIPES: the Castilian Vulgata of Boccaccio's DE CASIBUS VIRORUM ILLUSTRIUM}

\begin{abstract}
We know almost everything about the spanish translation of Giovanni Boccaccio's De casibus virorum illustrium, from XV century, and
\end{abstract}

* Para correspondencia, dirigirse a: José Blanco Jiménez (joblar@gmail.com), Departamento de Formación General, Universidad Santo Tomás, Vergara 317, Santiago, Chile. 
their containg codex. But, there are not studies about the vulgata text, stablished by the Sevilla's edition (1459), later copied in Toledo (1511) and Alcalá de Henares (1552). The variants and orders of the chapters could be result of the curator's manipulation or by the existence of a second archetype.

Keywords: Bocaccio, Caýda de príncipes, medieval latin literatura, spanish renacentist literatura.

Recibido: 02/11/14 Aceptado: 04/03/15

\section{LA TRADUCCIÓN CASTELLANA DEL $D E$ CASIBUS VIRORUM ILLUSTRIUM}

De las vicisitudes de la traducción castellana del De Casibus virorum illustrium nos ha dejado un relato completo Juan Alfonso de Zamora en una Arenga que precede el texto publicado por Meynardo Ungut alemán y Lançalo Polono compañero y que terminaron de imprimir en Sevilla el 29 de diciembre de 1495.

La reproduzco por primera vez de manera íntegra en edición diplomática ${ }^{1}$ :

Comiença el arenga que fizieron et ordenaron Juan alfonso de çamora secretario de nuestro señor el Rey de Castilla. E el muy reuerendo et sabio varon el doctor juan garcia dean enlas yglesias de santiago et segouia et oydor dela audiencia de nuestro señor el rey et del su consejo. E comiença assi. La qual dicha arenga ordenaron sobre el libro de juan bocacio. No deue ser oluidada por silencio la virtud de tineo.etc.Valerio libro.ix.titulo.c.iij. e assi por semejante no deue ser oluidada por silencio qual quier obra que para buena doctrina sea fecha. $\otimes \mathrm{E}$ como quier que comunmente la gente humana por ser de condicion flaca lo oluide al gran dios et saluador nuestro. Nuestro señor ihesu xristo que es sabidor et criador de todas las cosas no se oluida. Mas antes por que sea en remembrança perpetua auido por que della sea enxemplo et castigo a otros mueue las coraçones de algunos para que las tales obras escriuiendo se en libros o historiandose por pinturar a memoria sean reduzidos por

1 Con respecto a la necesidad de la edición diplomática, cfr. mi trabajo Blanco Jiménez 2013: 313-344. Para otras referencias, cfr. Petrucci 1977: 63-71 y Masai 1950: 177-193. 
esta razon. E otrosy por dulçura de gloria que enello toman los tales conponedores: por la memoria que dellos quedan: los que conpusyeron las notables et virtuosas obras: et las historias delos nobles fechos passados a los tales trabajos se mouieron et pusyeron. Onde el dicho valerio dize enel libro.viij.xv.c.v. No ha humildad enel mundo por grande que sea: que non sea tocada de dulçor de gloria. $\mathbb{C}$ E como yo juan alfonso de çamora: maguer non digno cauallero: secretario del muy illustre señor: nuestro señor el rey de castilla ouiesse auido el traslado romançado en nuestra lengua castellana del libro que conpuso Juan bocacio que es llamado de casibus illustrium virorum: que fue primero fecho en latin: el qual falle que no era acabado ni parescia por quien lo romançara. \C Porque del dicho libro fuy muy pagado por el su muy fermoso tractar et por que la noble doctrina que dende pueden tomar quales quier personas de qual quier condicion que sean tocada algun tanto dela dicha dulçor. Por este poquillo de trabajo que aqui tomo. Por tres cosas enesta parte a trabajar me opuse: La primera: la dicha obra por quien fuera romançada saber. La segunda: lo que del dicho libro fallescia para lo aqui continuar et auer. La tercera: de quien se opuso al trabajo delo romancar et a memoria traer. $\mathbb{C}$ E quanto a lo primero proseguiendo mi trabajo: supe en como el muy notable cauallero / et muy sabio et muy discreto señor don pero lopez de ayala: señor de ayala y de salua tyerra chanciller mayor de Castilla de loable memoria cuya anima dios perdone la dicha obra romançara et mucho me marauille / obra ser por el començada et non ser acabada. Las otras muy notables obras romanço el et fueron acabadas; assi como el Tito liuio et los Morales de job et otras algunas. E assy fuera esto saluo por que creo que lo embargo: o muerte suya al fazer: o ser el libro menguado por do lo romanço: o otro algund ympedimiento. $\mathbb{C} \mathrm{E}$ quanto alo segundo no lo podiendo fallar en castilla: oue lo en barcelona. El qual falle en latin: por quien me lo tornasse en nuestra lengua: alli fallar no pude. E despues aca en castilla asaz de letrados: dello requiriendo no me dauan aello remedio diziendo que la rethorica del / era muy escura para romançar. $\not \mathbb{E}$ porque a aquellos que en algunas buenas obras se ocuoan / siempre nuestro señor dios guia. Traxo a caso que en vno el muy reuerendo et sabio doctor Alfonso garcia dean de las yglesias de santiago et segouia: oydor dela audiencia del dicho señor rey et del su consejo. E yo por embaxadores del dicho señor rey: al rey de Portugal fuemos enbiados: enla qual embaxada como ouiessemos algunos espacios para exercitar nuestro espiritu: et veyendo yo la grand suficiencia que enel dicho dean hera para romançar lo que del dicho libro fallescia: et a ruego et ynstancia mia desse oponer al trabajo delo romançar ael plugo. E qual acabo lo que en el fallescia. E assy de diez libros que ay eneste dicho libro. El dicho señor pero lopez romanço los ocho: falta la meytad del capitulo que fabla del rey artur de Ynglaterra que es dicha la grand bretaña: et de 
Morderete su fijo. E dende en adelante romanço el dicho dean el diziendo et yo escribiendo. Los quales lo fizieron muy bien guardando su rethorica segund que por el paresce. E en quanto a lo tercero por que tal trabajo et obra como esta: callada so silencio no quedasse: maguer que sy ellos desto alguna gloria ouieron / non paresce por escriptura. Lo qual les es de alabar. Al honrra et en memoria suya el presente prologo et arenga ordene con algun tanto de administracion del dicho dean et mia. E en comienço deste dicho libro la asente. E assi concluyendo: puedo bien dezir las palabras suso escriptas: conuiene asaber. No deue ser oluidada por sylencio la virtud de Teseo.etc. Ni por semejante los que las tales obras fazen. Pues plega al nuestro señor dios: que al dicho pero lopez de ayala enla otra vida duradera adonde el es: en remuneracion deste trabajo et de todas las otras cosas et obras virtuosas que el fizo de parayso perpetuo. E al dicho dean et ami conel: que enla presente vida somos: nos dexe bien beuir et en su seruicio acabar. E despues enla otra: mas larga vida enla su sancta gloria nos quiera colocar: al qual et enel qual fue es et sera gloria et honor in secula seculorum Amen. Acabose esta obra de romançar enla embaxada recontada a treynta dias del mes de setiembre: año del señor de mill et quatrocientos et veynte et dos años (Ed. Ungut y Polono, Sevilla 1495, sign. Aij $\left.\mathrm{r}^{\mathrm{o}}-\mathrm{v}^{\mathrm{o}}\right)^{2}$.

Por lo tanto, quedan claras varias circunstancias.

En primer lugar, Juan Alfonso de Zamora tuvo en sus manos (no dice por qué razón) la traducción romanzada del libro De casibus virorum illustrium de Giovanni Boccaccio, pero estaba incompleta.

¿Era alguno de los códices que han llegado hasta nosotros? Desde ya respondo que no, por las variantes que presenta la edición impresa con el texto de todos los códices.

En segundo lugar, descubrió que el traductor era Pero López de Ayala y conjetura que éste detuvo (embargó) la traducción porque murió (muerte suya) o porque el libro estaba incompleto (menguado).

En tercer lugar, para proseguir el trabajo, no pudo conseguir el libro en Castilla, pero sí lo encontró en latín en Barcelona. Tampoco aquí sabemos de cuál códice pueda tratarse puesto que, hasta el momento, solo se conocen dos que tienen el texto completo: el Cod. 2246 de la Universidad de Salamanca (que proviene del Colegio Mayor de Toledo, donde tenía el $\mathrm{N}^{\circ}$

2 Este texto -que identificaré con la sigla Cay- está replicado en las ediciones de Toledo 1511 (CsT) y Alcalá de Henares 1552 (CsA). Se puede consultar en: http:// bibliotecadigitalhispanica.bne.es; http://bib.cervantesvirtual.com y se conserva en CD-ROM (Boccaccio 1495). 
4, y posteriormente del Palacio Real de Madrid, donde tuvo las colocaciones VIII.J.4 y 1120) y el Cod. 1.120 de la Biblioteca Nacional de Madrid. Solo el primero aparece citado en Nota al testo de RICCI-ZACCARIA y contendría la Redacción B. Su análisis es un trabajo por hacer.

En cuarto lugar, le fue difícil encontrar quien completara el trabajo, debido a que los letrados de Castilla decían que la retórica del texto lo hacía difícil de romançar. Finalmente, consiguió que ejecutara la labor Alfonso García de Santa María (más conocido como Alfonso de Cartagena), deán en las iglesias de Santiago y Segovia, oídor del Consejo del Rey.

En quinto lugar, declara que los libros eran diez, cuando en realidad son nueve. Esto me lleva a pensar que el antígrafo estaba dividido de esa manera.

En sexto lugar, la traducción de López de Ayala llegó hasta la mitad del Capítulo XIX del Libro VIII.

En séptimo lugar, el trabajo fue compartido: Alfonso García dictaba y Alfonso de Zamora escribía.

En octavo lugar, rinde un homenaje a Pero López de Ayala.

En noveno lugar, la traducción fue terminada el 30 de septiembre de 1422.

Quiero precisar que el texto traducido por López de Ayala llega hasta la frase El rey seyendo ya en la postremeria de sus dias luego que cayó del caballo, que corresponde a Rex autem dierum extremum iam sentiens continuo prosiluit ex equo navimque conscendens (VIII XIX 13) ${ }^{3}$.

\section{2. ¿CUÁLES SON LOS MANUSCRITOS QUE CONSERVAN EL TEXTO DE LA TRADUCCIÓN?}

Empecé a trabajar en el Caída de príncipes en 1975 y no había tenido tiempo para profundizar el tema del texto. Fue, por lo tanto, una agradable sorpresa descubrir que Isabella Scoma había publicado una edición crítica de los manuscritos, que considero resolutiva hasta el momento ${ }^{4}$.

Se trata de un buen trabajo, del que me limito a resumir los resultados.

\footnotetext{
Cas).

Todas las citas están tomadas de Boccaccio 1983 (lo cito de ahora en adelante como 4 Scoma 1993.
} 
Los códices que utilizó (y que identifico con mis siglas ${ }^{5}$ ) son los siguientes:

Cs $M^{2}$ (Scoma A) - Madrid, Biblioteca Nacional, Cod. 7.799 (olim V.329).

Cs $M^{3}$ (Scoma B) - Madrid, Biblioteca Nacional, Cod. 13.248 (olim Ff.278).

Cs $M^{1}$ (Scoma C) - Madrid, Biblioteca Nacional, Cod. 12.733 (olim Bb.52).

Cs E (Scoma D) - San Lorenzo del Escorial, Biblioteca del Real Monasterio, Cod. E.III.7.

Cs O (Scoma E) - San Lorenzo del Escorial, Biblioteca del Real Monasterio, Cod. L.II.14.

Cs P (Scoma F) - Madrid, Biblioteca de Palacio, Cod. 100 (olim IV.c.3).

De los que yo cité en su momento, no considera:

CsFD-Biblioteca privada de R. Foulché-Delbosc (actualmente el Cod. B 1196 de la Hispanic Society of America).

CsM - Madrid, Biblioteca Nacional, Cod. 955 (Olim E.6), que no es más que una copia de la edición de Alcalá de Henares (1552) realizada para Leonor de Fonseca.

Faltan también dos códices descubiertos recientemente, para los que ya he creado siglas, y que son citados por José Manuel Lucía Megías': CsW - Wien, Österreichische Nationalbibliothek, Cod. 6.030.

CsH - Cambridge, Harvard University, Houghton Library, Cod. Span. 67, que puede ser consultado en pds.lib.harvard.edu.

Aclaro de inmediato que, de los códices utilizados por la Scoma, solo el $C s$ $M^{2}$ está completo y al $C s M^{3}$ le falta la despedida de dedicatoria a Mainardo. El CsP llega casi hasta el final y el $C s O$ hasta casi todo el capítulo VI del Libro IX. Los otros manuscritos $\left(C s M^{I}\right.$ y $\left.C s E\right)$ se detienen donde llegó el trabajo de Pérez de Ayala.

Para ser más exactos:

- $\quad \operatorname{CsM}^{2}$ (Scoma A): Explicit [f. CCLXIJ r ro]: “... mas por la soberania de la fortuna que todas las cosas trastorna e rrebuelue. Deo gracias". Corresponde al Cap. CLXVIJ (Cas IX XXVII 11; Scoma p. 524, 61-63)

- $\mathbf{C s M}^{3}$ (Scoma B): Explicit [ f. CCXIII ro]: "por la sobervia de la fortuna que todas las cosas trastorna e revuelve". (Cas IX XXVII 11; Scoma p. 524, 61-63)

6 Lucía Megía 2001: 451-452. 
- $\quad$ CsM $^{1}$ (Scoma C): Explicit [f. $98 \mathrm{r}^{\mathrm{o}}$ b]: “ “.. otra ves tornar a batalla con el Rey Artur su padre...” Incompleto al final. (Cas VIII xIx 8; Scoma p. 452, 90-91)

- CsE (Scoma D): Termina [CLXI v ${ }^{\circ}$ : "El rrey seyendo ya lo postrimero de sus dias luego que cayo del caballo..." (Cas VIII XIX 13; Scoma p. 452, 114-115)

- CsO (Scoma E): Explicit: texto: $\left[332 v^{\circ}\right]$... fue tornado por ayuda de vn grario que auja ya fujdo en uetona y çegado de los... (mitad del Cap. CXLVII, De anulfo principe de los rromanos (Cas IX VI 15; Scoma p. 481, 54-55)

- CsP (Scoma F): Explicit [304 v b] “... E de buena mente ante desto enseria entre las cosas pasadas \& entre los otros a sancho rey de mayorcas \& llorauan que por obra..." (Cas IX XXvII 1; Scoma p. 523, 6-8)

De los manuscritos no considerados, puedo anotar lo siguiente:

- CsM: El colofón deja en claro que este manuscrito es solo una copia de la edición CsA. En los folios XXXv y LXXVI vo hay cuentas y nombres. Está en blanco que debía ser el $n^{\circ} \mathrm{XXXI}$. El libro II en el f. XXXII comienza incompleto. El f. LIII tiene recortada la miniatura; el f. CLIV está roto con deterioro del texto.

- CsG: Explicit [f. 190 v ]: "es a saber para caer en un punto quando a la fortuna pluguiere y pagar las penas a los que injuriastes. E por que alguna..." Texto incompleto, mútilo al final. Las citadas palabras del folio $2 \mathrm{r}^{\mathrm{o}}$, que señalan la fecha, corresponden al final del Prólogo y Arenga de Juan Alfonso de Zamora. De este manuscrito no tengo mayores informaciones, pero el texto final corresponde a IX XXVII 8 [ea vos lege augem conscendisse volubilis orbis, qua ceteri ruituri - scilicet si libuerit in puncto - penasque offensis daturi. Et ne vos aliquali] y la traducción es la misma de la edición impresa, puesto que Scoma lee quanto en vez de quando y porque por alguna manera en vez de e por que alguna. Me da la impresión que es mucho más probable que el manuscrito sea una copia de una de las ediciones a que éste sea la base de las ediciones.

- CsH: El texto se interrumpe en: [f. $162 \mathrm{v}^{\mathrm{o}}$ a] ... tornar a la batalla contra el rey artur su padre" (Cas VIII XIX 8; Scoma p. $452,91)$ y prosigue de inmediato en la columna siguiente [f. 162 $\mathrm{v}^{\mathrm{o}} \mathrm{b}$ ]: "Diogenes llamado romano sy fue llamado ytaliano de nascimiento..." (Cas IX IX 1; Scoma p. 487, 1). Explicit [175 vo a] “...\& sy acaesciere que / seades derribados, paresca que / non es fecho por Vuestra maldat. / mas por la sobervja de la fortuna /, q' todas las cosas trastorna / \& rebuelve". 
- CsFD: Explicit [f. CCLXXVIJ r r b] ... no es fecho por vuestra maldad mas por la soberuja de la fortuna que todas las cosas trastorna $\&$ buelue / finitur libro Re / datur gloria $\chi \rho o$ / € Acabose este libro de escri / bjr enla villa de brujas a / XXX dias del mes de diziem / bre año del señor de mjll / \& quatroçientos \& setenta / \& seys Años . ." Tablas en los ff. IIJ $\mathrm{r}^{\mathrm{o}} \mathrm{b}-\mathrm{VJ} \mathrm{v}^{\mathrm{o}} \mathrm{b}$. Falta la arenga introductoria de Juan Alfonso de Zamora, por lo que se puede presumir que no estuviera en el antígrafo.

- CsW: Escritura cursiva del siglo XVII, 463 ff., Historias en romance Clamada Cayda de principes desde Adan y Eva hasta la muerte del rey Don Felipe III. d'España. Explicit: ... A nuestro claro monarca y alteran catolica contra los mandamientos dela yclesia Romana. Amen. Perteneció a Pedro de Navarra y de la Cueva (Marqués de Cabrega, Madrid, siglo XVII).

\section{3. ¿CUÁL ES EL STEMMA CODICUM DEL TEXTO DE LA TRADUCCIÓN?}

Revisando los citados testimonios, Isabella Scoma estableció un texto crítico basado en Cs $M^{2}$-acompañado por un excelente y exhaustivo aparato filológico- elaborando un stemma codicum, que se despliega de la siguiente manera: de un arquetipo $\omega$ se pasa, paralelamente, a una tradición $\alpha$ (compuesta por $C s O$ y un subgrupo $C s M^{2}$ y $C s P$ ) y una tradición $\beta$ (compuesta por $C s M^{1}$ y un subgrupo $C s E$ y $C s M^{3}$ ).

Puedo agregar que los manuscritos que no alcanzó a considerar son clasificables de esta manera:

CsM es copia de la edición CsA; $\mathrm{CsG}$ sigue el texto de Cay; $\mathrm{CsH}$ tiene un texto igual a Scoma y es afín a $\mathrm{CsM}^{2}$ (Scoma A); CsFD es afín al grupo $\beta$ establecido por Scoma (variantes de $\mathrm{CsM}^{3}$ - Scoma B y $\mathrm{CsM}^{1}$ - Scoma C). $\mathrm{CsW}$ es un caso aparte: escrito en el siglo XVII, por lo que he podido examinar hasta el momento, reproduce una traducción completamente distinta a la de Ayala y Cartagena.

La estudiosa concluyó, fundamentadamente, que Pero López de Ayala se habría servido de un texto del Grupo I de la Familia B. Esto lo veré más adelante, sin entrar en el mérito del valor y características de la traducción, que no forma parte de los objetivos de este trabajo. En efecto, considera que ésta tiene características que la diferencian de la de Alfonso de Cartagena, 
en especial en lo que se refiere a los cortes, los agregados, las apelaciones al lector y el uso de la amplificatio ${ }^{7}$.

Isabella Scoma no consideró el texto de las ediciones, de las que entrega una completa descripción y bibliografía. Éstas fueron copiadas, sucesivamente, la una de la otra, como también he podido comprobar:

CsS - Sevilla 1495, Meynardo Ungut y Lançalo polono, $156 \mathrm{ff}$.

CsT - Toledo 1511, sin tipografía, $127 \mathrm{ff}$.

CsA - Alcalá de Henares, Jusn de Brocar, 144 ff.

Es justamente ese texto -que considero la Vulgata castellana-con el que he estado trabajando desde hace años y que presenta profundas diferencias con el establecido a partir de los manuscritos (que identificaré como Scoma). De ahora en adelante, haré referencia siempre al texto impreso (que siglaré Cay), en comparación con el editado por la filóloga italiana.

\section{LAS DOS REDACCIONES DEL DE CASIBUS}

Ya en 1963, Pier Giorgio Ricci demostró que la Redacción B es la más tarda por varias razones que resumo a continuación'

En primer lugar, identificó la desaparición de las cláusulas rítmicas en la redacción más larga. El cursus velox no aparece, porque el orden de las palabras es diverso y sustituye la palabra cuadrisílaba con una trisílaba de significado equivalente ${ }^{10}$.

Después, entre 1350 y 1363, Boccaccio enriquece notablemente sus conocimientos culturales por su relación con Petrarca y con el calabrés Leoncio Pilato, que tradujo la Ilíada y la Odisea y empezó a enseñarle el griego. Además, intensificó sus contactos con amigos florentinos, napolitanos $\mathrm{y}$ vénetos.

Limitándose al Primer Libro, Ricci analizó 11 lugares que presentan variantes entre las dos redacciones y que yo expongo en el próximo párrafo.

Scoma: LII.

Scoma: XXVIII; Blanco Jiménez 1977: 47.

Ricci: 179-188.

Ricci: 179-183. 
Habiendo establecido que la Segunda Redacción (B) es la más tardía (y también la más larga), sigue a Hauvette y Torraca en lo que se refiere a su fecha de composición ${ }^{11}$, fijándola alrededor de 1360. Las razones son las siguientes: el último hecho histórico que se recuerda es la batalla de Poitiers (1356) y la prisión de Juan el Bueno en Inglaterra; al comienzo del libro VIII hay un diálogo entre Boccaccio y Petrarca, que podría aludir a la visita que el primero hizo al segundo entre el 16 y fines de marzo de 1359; no hay palabra alguna acerca de los poemas homéricos y de Leoncio Pilato, que estuvo en relación con Boccaccio de 1359 a 1362.

En cuanto al año de la revisión, que habría de determinar la redacción definitiva, habría tenido lugar hacia fines de 1373 o comienzos de 1374. Esto porque, en su dedicatoria a Mainardo Cavalcanti (que está presente solo en algunos manuscritos que contienen la primera redacción) señala que fue padrino de bautizo del hijo de éste, que se casó con Andreola di Iacopo Acciaiuoli en la primavera de 1372. Además, Francesco Petrarca figura como persona viviente.

Vittorio Zaccaria -que tomó a su cargo la edición del De Casibus después de la prematura muerte de Pier Giorgio Ricci- en general estuvo de acuerdo con estas fechas ${ }^{12}$ y las confirmó en la Introducción a la edición crítica ${ }^{13}$. Revisando los datos ya adquiridos, sostuvo que la nueva redacción fue iniciada antes de la composición de la dedicatoria (que sería de 1373) y estuvo terminada antes de octubre 1374, cuando Boccaccio recibió la noticia de la muerte de Petrarca.

Esa Segunda Redacción (B) se divide en dos grandes grupos, que son identificables sobre la base de lagunas comunes y de lecciones típicas, que son comunes a todos o parte de los representantes. El Primer Grupo (I) tiene su principal representante en el Cod. Palatino lat. 935 de la Biblioteca Apostólica Vaticana, Ciudad del Vaticano (Vp) y el Segundo Grupo (II) tiene su principal representante en el Cod. Ottoboniano lat. 2145 de la Biblioteca Apostólica Vaticana, Ciudad del Vaticano (Vo).

Comparando ambos grupos, Zaccaria llega a la conclusión de que el Grupo I es mejor desde el punto de vista textual que el Grupo II y, entre otras consideraciones, añade que hay pocos casos de lecciones deteriores

Hauvette 1911: 279ss.; 1914: 348; Torraca: 207-213.

Zaccaria 1977-78: 23-26.

Zaccaria 1983: Introduzione: XV-XX. Debo agradecer una vez más a la ya fallecida Sra. Adriana Materassi, viuda del Prof. Pier Giorgio Ricci, por haber puesto a mi disposición el dactiloscrito de su marido, como asimismo las fotocopias que aún conservo. Acerca del trabajo de Ricci, cfr. Zaccaria 1983: Nota al testo: 897-881. 
en el Grupo I: si se encuentran en Vp, los otros exponentes en general lo denuncian y corrigen el descuido (y naturalmente colman las lagunas). Es significativa también la casi total coincidencia con $\mathrm{Vp}$ de los probables descendientes del Cod. V 9 de la "parva libraria" (que podría haber sido un autógrafo de Boccaccio), esto es del Cod. Pluteo XXVI sin. 6 de la Biblioteca Mediceo-Laurenziana, Florencia (L), del Cod. Pluteo LII 29 de la Biblioteca Mediceo-Laurenziana, Florencia ( $\left.\mathrm{L}^{1}\right)$, del Cod. Clmae 425 (ex Vienés 437) de la Magyar Nemzeti Múzeum. Országos Széchényi Könyvtár, Budapest (Bp) y del Cod. Urbinate lat. 451 de la Biblioteca Apostolica Vaticana, Ciudad del Vaticano (Vu). Además Vp (y su grupo) concuerdan casi constantemente con la Redacción $\mathrm{A}^{14}$.

Zaccaria explica la presencia de los códices contaminados con algunas hipótesis, que establecen que ya en vida de Boccaccio, o inmediatamente después de su muerte, circularon diversos tipos de copias ${ }^{15}$.

Con respecto al estado del testo de los 64 manuscritos identificados, Zaccaria los clasifica de la manera siguiente: REDACCIÓN A (36 manuscritos, con 10 contaminados) y REDACCIÓN B (36 manuscritos; 14 de Primer Grupo y 22 del Segundo Grupo) ${ }^{16}$.

\section{5. ¿CUÁL DE LAS DOS REDACCIONES FUE LA QUE PÉREZ DE AYALA TUVO A DISPOSICIÓN?}

Para apoyar su demostración de la existencia de las dos redacciones, como ya señalé, Ricci analiza 11 lugares específicos. Yo confirmaré esos resultados citando también el texto establecido por Isabella Scoma (Scoma, con los números de páginas y de líneas) y de las ediciones impresas (Cay, con la identificación del folio y la columna), pero me limito a tres ejemplos:

$\mathbf{1}^{\circ}$ - Boccaccio actualiza el texto, adecuándolo a sus nuevos conocimientos acerca de la cultura grecorromana, esto es con una referencia que se encuentra en Genealogia (II, 63), donde Cadmo está puesto junto a la fuente de Hipocrene, que estaba consagrada a las Musas. Corresponde a

14 Zaccaria 1983: Nota al testo: 885-896. Todas las siglas referidas a los códices que contienen el texto latino están identificadas en las pp. 875-878.

15 Zaccaria 1983: Nota al testo: 883.

16 Zaccaria 1983: Nota al testo: 881-896. 
la última revisión de Cas, porque el nombre de Hipocrene está agregado al margen del folio $30^{a}$ en el autógrafo de la Genealogia (cuyo texto fue escrito alrededor de 1371).

A: Et cum iam non solum regno, sed fulgore quodam scientie, qua excogitaverat literatum caracteres, et doctrina rudibus indoctisque populis dederat (I vi 3).

B: Et cum iam non solum regno, sed fulgore quodam scientie, qua apud Libetridem fontem excogitaverat literatum caracteres, et doctrina rudibus indoctisque populis dederat (I vi 3).

Scoma: e aver poderío de regno, mas aun con resplendor de çiençia, qua avía cobrado quando llegara a la fuente llamada Libetride: de cada dia enseñava letras a los pueblos rudos et synples (p. 25, 21-23).

Cay: et a ver poderio de reyno: mas avn con muy grand resplandor de sciencia que hauia cobrado quando llegara ala fuente llamada libetrides: et de cada dia enseñaba letras alos pueblos rudos et simples (f. vij $\mathrm{r}^{\circ} \mathrm{b}$ ).

$2^{\circ}$ - En la segunda redacción no se limita a narrar que Hipólito es arrastrado por los caballos, muerto y desgarrado, sino que agrega datos tomados de Genealogia (X, 50):

A: Erat quippe durum et luctuosum etiam hostibus, nedum patri suisque, trucidati per invia loca cadaveris spectaculum. Attamen, ut qui tristis amici casu suo carcere dolens et turpi nece filii miser erat, alio insuper feriretur ictu, semisopitos infauste Phedre ignes dilectissimi iuvenis infortunium et pietas non solum suscitavere, sed in longe maiores extulere flammas (I x 23-25).

B: Erat quippe durum et luctuosum etiam hostibus, nedum patri suisque, trucidati per invia loca cadaveris spectaculum. Sunt tamen (nec levis auctoritatis homines) qui negent Ypolitum hoc infortunio mortuum, sed ab amicis occultatum repente, et eum mortuum fama vulgatum, et demum vigilantia et arte Esculapii sanitati redditum. Attamen, ut qui tristis amici casu suo carcere dolens et turpi nece filii miser erat, alio insuper feriretur ictu, semisopitos infauste Phedre ignes dilectissimi iuvenis infortunium et pietas non solum suscitavere, sed in longe maiores extulere flammas (I x 23-25).

Scoma: tal cosa non tan solamente al su padre, mas aun a los enemigos de ver dura e manzillada, como los sus miembros por unos lugares espantables yazían despedaçados. Son enpero algunos estoriadores, e asaz de grant autoridat, que dizen que Ypólito non murió desta tal manera, mas que fue tomado escondidamente de algunos sus amigos e que fizieron fama que era muerto, e que finalmente con artes e sabidoría de Esculapio fuera tornado a ver sanidat. Enpero, el que triste por el acaesçimiento del su amigo e dolioso en la cárçel do estaba por la muerte torpe e mala del fijo, estava mezquino, aún otra ferida ovo más. $\mathrm{Ca}$ los fuegos, ya como medio amansados, de la desaventurada Phedra, la desaventura del muy amado mançebillo e la piedat non tan solamente 
los despertaron, mas aún ençendieron e levantaron mayores llamas. Ca, como otese Phedra el desaventurado acaesçimiento de Ypólito, maguer que dende tarde se arrepentía (p. 42, 100-114).

Cay: la qual cosa no tan solamente fue dolorosa et amarga de oyr al triste padre suyo: mas alos sus enemigos contrarios fuera amarga et dura dee ver: mayormente quedando sus miembros fechos pedaços por vnos lugares muy espantables: por manera que no ouo ninguno que trabajasse delo yr a buscar: avn que algunos historiadores de grande auctoridad dizen que ypolito no murio de tal manera: mas que fue tomado escondidamente por algunos de sus amigos. Los quales fizieron fama que era muerto de tal manera como auedes oydo. Et con las artes et sabiduria de Esculapio fue retornado et ouo sanidad. Enpero el que muy triste por el casamiento de su amigo et muy dolioso et triste enla carcel donde estaua por su muerte.et ya venido en su reposo por hauer plazer et folgar. Et como de cabo torno a ser muy mal dolioso et amargo por la torpe muerte de su fijo. Y estando assy triste et mezquino. Otra ferida ouo mas. Ca los fuegos et clamores amansados de Fedra: la qual oyendo como mueriera despedaçado aquel mancebillo fue mucho querido et amado por tan desauenturada muerte fue muy turbada et triste sino que tarde se arrepintio (f. xiij $\left.v^{\circ} a-b\right)$.

$3^{\circ}$ - Completa la lista de los impedimentos que se oponían a la victoria de los griegos y que fueron removidos por Ulises, según se dice en Geneaologia XI, 40:

A: Et ne per cuncta passim transvadam, cum iam subtractum Palladium et spem pacis et salutis ablatam vidisset omnem, noctu... (I XIII 17).

B: Et ne per cuncta passim transvadam, cum iam subtractum Palladium, demptos Teucri regis cineres, deductos ante gustatum Xantum Rhesi niveos equos, et spem pacis et salutis ablatam vidisset omnem, noctu... (I XIII 17).

Scoma: E, porque non alengue mucho la tal estoria nin espienda mi tiempo en este solo contar, después que perdido e furtado el Paladión; después que los caballos blancos bevieron en el río Xanto; después que Príamus vio todo su bien e toda su esperança perdida (p. 53, 98-102).

Cay: E por que no aluenge mucho esta historia. Ni passe mi tiempo en solo esto contar, despues que perdido et furtado el paladio: et los cauallos blancos beuieron enel rio xantus: et como todas estas cosas fueron vistas por el rey Priamus: alli conoscio todos sus bienes aver los perdidos et partio de su memoria toda esperança de bien (f. xvij $v^{\circ} a$ ).

Resulta claro que el texto de las Caýdas sigue la Redacción B, pero -tanto en Scoma como en $\mathbf{C a y}$ - omite algunas palabras y agrega algunas frases apócrifas. Zaccaria sostiene que Boccaccio tal vez divulgó su ejemplar de servicio $\alpha$ con el texto de la Primera Redacción no mucho antes de componer la dedicatoria para Mainardo (que tal vez se difundió también aparte). Parece 
que Boccaccio dejó copiar de su segundo ejemplar de servicio $\beta$ también el texto refundido sin dedicatoria. Es así como se explica que, en la tradición manuscrita, existan códices de ambas redacciones con y sin dedicatoria. En conclusión, los ejemplares de servicio fueron arquetipos de los manuscritos sin dedicatoria, tanto de la primera como de la segunda redacción; la copia de Mainardo fue arquetipo de los manuscritos de la segunda redacción con dedicatoria ${ }^{17}$.

Isabella Scoma señala varios otros pasajes que hacen coincidir su texto con la Redacción $\mathrm{B}^{18}$. Todo esto en lo que se refiere a la traducción de López de Ayala; el texto de Cartagena queda para más adelante.

Mientras tanto, me parece imprescindible evidenciar que existen otras VARIANTES, de las cuales me permito señalar apenas dos, escogidas de muchísimas otras. Y las tomo de aquellas establecidas por Pier Giorgio Ricci (y revisadas por Vittorio Zaccaria), que corresponden al Libro I:

\section{$1^{\mathrm{a}}$ - Eva muere (I I 15)}

A - B: eademque lege Eva senio fessa defecit

Scoma: asý vieja e ançiana de tiempo allí yogó $(p .14,119)$

Cay: la qual ansi vieja et anciana allí espiro (f. iiij $\mathrm{r}^{\mathrm{o}}$ a)

$2^{\text {a }}$ - Nembrot (I III 3)

A: ut quod in eum accepisset consilium frustraretur

B: ut appareret consilii cepti vanitas

Scoma: que porque paresçiese vanidat et comienço desta cosa (p. 18, 21-22)

Cay: que porque paresciesse vanidad el comienzo de esta cosa (f. $\left.v \mathrm{r}^{\circ} \mathrm{a}\right)$

Hay que notar que, muchas veces, los textos no corresponden. Me refiero a este tema más adelante entre los CAMBIOS DEL TRADUCTOR.

\section{6. ¿ES POSIBLE ESTABLECER LA DEPENDENCIA DE LA TRADUCCIÓN DEL GRUPO I DE LA REDACCIÓN B?}

Asumido que, en general, Pérez de Ayala siguió un texto de la Redacción $\mathrm{B}$, queda por aclarar a cuál de los dos grupos pertenecía ese manuscrito. 
Como ya señalé, Ricci -acogiendo las indicaciones de Hauvette y Torraca- fija el término de la Redacción A en 1360 (cfr. nota 11). Para ello -además de los textos ya examinados-se apoya en algunas constataciones ${ }^{19}$, que paso a enumerar:

$1^{\circ}$ El último hecho histórico citado en el De casibus es la batalla de Poitiers (1356) y la prisión de Juan el Bueno en Inglaterra.

$2^{\circ} \mathrm{Al}$ inicio del Libro VIII hay un diálogo entre Boccaccio y Petrarca, que es referible a una estada prolongada del primero donde el segundo (1359), cuando Boccaccio se detuvo en Milano desde el 16 de marzo hasta los últimos días de ese mes.

$3^{\circ}$ En la primera redacción del De Casibus no hay una sola palabra que presuponga el conocimiento de los poemas homéricos y la enseñanza de Leonzio Pilato. La relación con Leonzio ocurrió entre 1359 y 1362. Cualquier referencia al asedio de Troya viene de fuentes latinas, de los comentaristas de Virgilio y de compilaciones medioevales (también en vulgar).

$4^{\circ}$ No hay derivación alguna de Tácito.

¿En cuál año llevó a cabo la larga revisión que determinó la redacción definitiva?

Según Ricci, la llevó a cabo indudablemente después de haber conocido a Tácito y los poemas homéricos. Después de 1362 y nos ayuda la carta dedicada a Mainardo Cavalcanti en la que asegura que ha tenido a bautismo el hijo de éste. Como Mainardo se casó con Andreola di Iacopo Acciauoli en la primavera de 1372 y, como en las últimas páginas del De casibus se refiere a Petrarca como de persona viva (cfr. IX, XXVII, 6), estamos hablando de fines de 1373 o de los primeros meses de 1374.

A este punto resulta absurdo pensar que López de Ayala pudo llegar a cabo su trabajo a partir de la versión francesa de Laurent de Premierfait ${ }^{20}$. Además de que falta una demostración filológica interna, baste pensar que el humanista francés se sirvió del texto $\mathrm{A}^{21} \mathrm{y}$ tradujo también la Dedicatoria. Pero yo quise tener la opinión de la persona más calificada para emitir una opinión al respecto, esto es Isabella Scoma.

He aquí la traducción de su respuesta: 
"Egregio Profesor,

Estoy en conocimiento de la hipótesis avanzada acerca de la posibilidad (subrayo posibilidad y no certeza) que Pero López de Ayala haya ejecutado la Caýda teniendo delante de sí el texto del De casibus en lengua francesa de Laurent de Premierfait.

Ahora bien, como Usted mismo afirma, no ha sido entregada hasta hoy a favor de esta tesis prueba filológica alguna y, por lo tanto, en ausencia de ella, no se puede en modo alguno avalar esta idea.

Entonces me pregunto: ¿por qué Ayala habría debido servirse de una traducción en francés desde el momento que estaba en grado de comprender (digo comprender) el latín (ver las otras traducciones ejecutadas por él)?; y es más: ¿por qué habría debido hacer uso de un texto en lengua francesa, siendo, como es sabido, vastísima la tradición latina del De casibus (cerca de 72 manuscritos) y más difundida? ¿No le parece, por eso, que, en Avignon, donde se piensa que Ayala haya tenido modo de conocer el texto boccacciano, el escritor ibérico poder encontrar más fácilmente un texto latino del De casibus más bien que una traducción en francés?

La estrecha parentela entre la Caýda y el De casibus que emerge de mi estudio me ha llevado a desatender una derivación de la Caýda del texto de Laurent de Premierfait, a pesar de darme cuenta hoy que sólo un examen estrictamente filológico, un cotejo ejecutado palabra por palabra entre el texto castellano, la versión francesa y también el texto latino, entregaría una respuesta al problema que Usted me presenta... Cordiales saludos. Isabella Scoma”.

Obviamente, no estoy en condiciones de llevar a cabo ese cotejo, pero sí de comparar las fichas Ricci-Zaccaria con los textos de Scoma y Cay. Y quiero empezar con aquéllas que permiten dividir la Redacción B en Grupo I (Vp y afines) y Grupo II (Vo y afines). Pero ese trabajo lo realizó también Isabella Scoma que - examinando esas fichas-identificó una serie de lagunas comunes a los exponentes del Grupo II, que confirmaban la dependencia de su texto del Grupo I ${ }^{22}$, y que había una serie de lecciones características que, a pesar de la diversidad de la lengua, estaban testimoniadas por los representantes del Grupo I contra las del $\mathrm{II}^{23}$.

Por mi parte, yo agrego, estos pocos ejemplos entre otros muchos:

\footnotetext{
Scoma: XXXV-XXXVI.
}

23 Scoma: XXXVI-XXXVII. 
$1^{\text {o }}$ - Adán y Eva declaran (I i 2)

A: Inimico suadente dyabolo Fortune lubricum primi experti sumus

B: Inimico suadente homini Fortune lubricum primi experti sumus

B (Vo-II): Inimico suadente omne Fortune lubricum primi experti sumus F- B (Vp-I): Inimico suadente omne Fortune ludibrium primi experti sumus

Scoma: et con engaños et falsos amonestamientos del diablo caymos et avemos ya prouado el estado flaco et deleznadero dela fortuna (p.11, 14-15)

Cay: et con engaños et falsos amonestamientos del diablo caymos et avemos ya prouado el estado flaco et deleznadero dela fortuna (f. iij r $^{\circ}$ a)

$2^{\circ}$ - Caín arrepentido se esconde en los zarzales, pero hay referencia a las guaridas de las fieras (I I 13). Zaccaria anota que las palabras lustraque ferarum de A faltan en II: de los mss. I algunos - entre los cuales Vp - llevan sólo lustra o agregan al margen ferarum (p. 914):

A: inter vepreta lustraque ferarum delitescentem, nepotis sagitta confussum

B (Vo - II): inter vepetra delitescentem

Scoma: escondiéndose entre los zarçales, aconpañado de las bestias fieras e bravas, finalmente muerto con saeta del su nieto (p. 14, 106-108) Cay: escondiendo se: entre los çarçales acompañado de bestias fieras et brauas et final mente muerto con saeta de su nieto (f. iiij $\mathrm{r}^{\mathrm{o}}$ a)

N.B.- Scoma/Cay siguen B (Vo-II): no está lustraque (y guaridas)

$3^{\circ}$ - In excusationem Alcibiades (III XIII 10)

B-I: Et hic Alcibiades, variis consternatus rebus, usque in nostrum evum eximio fulgore nomen deduxit suum

B-II: Et hic Alcibiades, variis consternatus rebus, usque in nostrum evum nimio fulgore nomen deduxit suum

Scoma: E este Alçibíades, pasando muchas e diversas fortunas, resplandesçiendo dexó el su nombre fasta este nuestro tiempo (p. 185, 64-66)

Cay: et asi este alcibiades del pasando muchas et diuersas fortunas resplandeciendo. dexo su nombre fasta este nuestro tiempo (f. liij $\mathrm{r}^{\mathrm{o}} \mathrm{b}$ )

En el último caso, se elude la traducción y ello ocurre a menudo. Desgraciadamente, no estoy en condiciones de asegurar si por elección del traductor o porque la o las palabras faltaban en el antígrafo latino.

Ahora bien, como ya señalé, Ricci y Zaccaria han identificado el Grupo I con el Códice Vp (Cod. Palatino lat. 935 de la Biblioteca Apostólica Vaticana) y el Grupo II tiene su mejor representante en Vo (Cod. Ottoboniano lat. 2145 de la Biblioteca Vaticana), que Ricci escogió para su edición crítica y que podría haber sido transcrito cuando aún estaba vivo Boccaccio e, incluso, del ejemplar que regaló a Mainardo. 
Según Zaccaria, el primer grupo se comporta de modo conforme a la tradición de la primera redacción, lo que lleva a pensar que las lagunas y las lecciones diversas de los exponentes del grupo de Vo se deben a distracciones o a intervenciones del copista de su arquetipo (que, si no es el amanuense de Vo, podría ser de poco antes).

Al respecto, el mismo Zaccaria recuerda que el copista Raffaele de' Marcatelli (1495) fue capaz de colmar, obviamente disponiendo de un ejemplar del primer grupo, una vez completada la transcripción, algunas de estas lagunas al margen de su manuscrito $(\mathrm{Ga}-\mathrm{Cod} .134$ de la Bibliothèque de la Ville e del'Université de Gand).

Con todos estos antecedentes, resulta una tarea ardua identificar el texto que siguió Pero López de Ayala. Las variantes son muchísimas y mostraré solo algunas en la siguiente sección. Además, como ya he puesto en evidencia, el texto impreso difiere notablemente de los textos manuscritos.

Solo un estudio profundo del texto castellano y una revisión de todos los manuscritos que se conservan permitirían descubrir cuál es el antígrafo. Pero tampoco tenemos la certeza de que aún exista físicamente. Además, como ya es posible constatar en los ejemplos señalados, las intervenciones de los traductores y de los impresores son muchísimas.

\section{ALONSO DE CARTAGENA SE SIRVIÓ DE UN TEXTO DE LA REDACCIÓN A}

Isabella Scoma sostiene esta posibilidad señalando importantes lagunas del texto B, que están presentes en la traducción de Cartagena ${ }^{24}$. A ellas quiero agregar un importante pasaje, que ha servido para fijar la segunda datación del De Casibus:

A: (IX XXVII 5-6) exorbitatum est a veritatis tramite sapientum emendationi relinquo. Si vero quenquam labore isto meo...

B: (IX XXVII 5-6) exorbitatum est a veritatis tramite doleo; attamen, cum humanum peccare sit, compatiendum ignorantie mee est, non arrogantie imputandum. Sane, ne perseverando videar eterni luminis hostis, queso perdulce atque preclarum phylosophie decus prudentiores indulgeant. 
Et is potissime, qui tempestate hac splendidissimum tam morum spectabilium quam commendabilium doctrinarum iubar vividum est, Franciscus Petrarca laureatus, insignis preceptor meus, equa cum ceteris caritate agat, ut suppleatur quod omissum sit, et superfluum resecetur, et si quid minus forsan christiane religioni seu phylosophice veritati sit consonum - quod me advertente nil est-emendetur in melius. Si vero quenquam labore isto meo...

Scoma: he salido de la senda de la verdat, déxolo a hemienda de los sabidores. E sy por ventura por este mi trabajo (p. 523, 30-32)

Cay: he salido dela senda dela verdad / dexolo a enmienda de los sabios y entendidos. E sy por ventura por este mi trabajo (f. cxlix $r^{\circ}$ a)

Queda claro que no se menciona a Petrarca, porque no estaba en el texto original. En todo caso, su presencia en la Redacción B, que permitiría datarla antes de octubre de 1373, podría tratarse -como propone Zaccaria- de una mención "per consuetudine letteraria, anche dopo aver appresa la dolorosa noticia della sua morte" 25 .

Entrego otras variantes de la traducción de Cartagena:

- IX III 5-8: O bone Deus, quam fera pestis cupido! Mirantur non nulli ab hac letis in rebus mentes quandoque laqueari atque vinciri; quid si, non dicam mediis in lacrimis seu inter armorum fragores, verum in obsessos in plenum tela iacientem videant? Sed de hoc alias. Capta igitur Romulda infelix uritur, nec sui compos, muliebri rubore posito incliti viri vulneribus adhuc cruore recenti manantibus, clam per internuntios adversario regi, si suas velit nuptias celebrare, castri pollicetur dominium. Rex, esto barbarus, cognita muliebri libidine ac vilipensa, imperii cupidus, petitis annuit; et sic clam Avares in castro recepti, omnes occidere viros, mulieribus in servitium reservatis, inter quas filie due Romulde-cum filii aufugissent- deducte sunt. Romulda autem, ex excidio suorum ductura triunphum, regis iussu induta regalibus

Scoma: ¡Oh buen Dios, quán fiera pestilençia es la cobdiçia de la luxuria! Maravíllanse algunos como estando las cosas alegres las voluntades enlaxadas della, mas aun más es esto que non solamente en la metad de las lágrimas e entre el estruendo de las armas, mas aun en los çercados echa enteramente sus dardos. Mas esto quede para otro lugar. E Romulda desaventurada quemando ansý, menospreciando el ynperio, consintió en lo que le dixeron e metió escondidamente a los Avaros en el castillo, los quales mataron a todos los varones e guardaron las mujeres para servicio, 
entre las quales fueron traídas dos fijas de Romunda, e los fijos fuyeron. E Romunda que con tanta destruyçion de los suyos quería trihunpho, por mandado del rey fue vestida en paños reales (pp. 472-473, 30-42)

Cay: $€$ O dios todo poderoso que fiera pestilencia es la cobdicia dela luxuria: et como se marauillan algunos como estando las cosas por otras maneras tractadas: estando las voluntades alegres et muchos ser enlazados desde ardor suzio luxurioso. Mas desta digamos que avn estado enla mitad de las lagrimas mirando el estruendo delas armas de su enemigo que la tenia cercada: et la destruya la tierra: et la auia muerto su marido: ouo lugar et poder enella este malicioso pecado: que enlos tristes llorosos llenos de perdidas et trabajos et cercados conplidamente echase este pecado sus dardos. Mas esto quede para otro lugar: et romilda desauenturada cocluyda de su mal pensamiento desanparo et menosprecio su noble ynperio consintiendo en todo lo que le dixeron: procurando su desordenado deseo: metiendo escondida mente los caualleros del rey que cercada la tenían en su castillo. Los quales mataron todos los varones et dexaron las mujeres para su seruicio entre las quales fueron leuadas dos fijas de romilda et los fijos fuyeron: et romilda que con destruycion delos suyos quiso triunfo de reynar et ya dispuestas por mandado del rey fue mandada vestir en paños reales: (f. $\operatorname{cxxxiv~} \mathrm{r}^{\mathrm{o}}$ a).

Resulta obvio que Scoma (ya no se consideran los mss. C-CsM $M^{1}$ y D-CsE) presenta un texto simplificado con respecto a Cay. Por otro lado, este último muestra variantes irreconciliables con el texto de Boccaccio, como caualleros en vez de Avaros. (B-M $\mathrm{M}^{3}$ lee: varones) La única posibilidad coherente es que el editor "haya corregido" el texto. Menos probable es que en el texto manuscrito, al copiar de la edición, el copista hubiera decidido compendiarlo y "mejorarlo".

- IX XII 1: Currus et exuvias vestre dicate Veneri et triunphi titulos eneis in tabulis figite

Scoma: e aparejad a vuestra Venus grandes carror e fincat en tablas de alanbre los títulos de vuestros triunphos (p. 491, 10-12)

Cay: E aparejad a vna venus grandes carros et fincad en tablas de aranbre

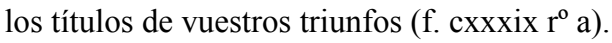

Se traduce aeris filum como "alambre", pero aeneis debería ser "de bronce". Obviamente, la lección ambigua tiene que haber estado en un arquetipo común.

Eric W. Naylor no ve "ninguna diferencia entre la primera y última parte de la traducción que indique la presencia de otro traductor". La existencia del Prólogo se explicaría porque los impresores lo encontraron "en una 
versión -ahora perdida - terminada por Cartagena y que fue juntado por ellos en otra versión de la traducción completa hecha por don Péro López" ${ }^{26}$.

Además de que el trabajo de Isabella Scoma demuestra lo contrario, creo que es significativo que algunos de los manuscritos incompletos se detengan precisamente en el capítulo hasta el que llegó el Canciller. Por otro lado, el códice $C s H$ tiene también una laguna en ese capítulo, a pesar de que el texto se retoma más adelante.

Creo que la difusión de Scoma y de Cay fue paralela. Los traductores fueron dos y la versión incompleta de Pérez de Ayala circuló antes de que Zamora se preocupara de completarla. Más tarde, cuando éste dispuso de la traducción de Cartagena, unió ambos textos (tal vez tuvo en su poder el autógrafo del Canciller) dando origen a un arquetipo, que sirvió tanto para los manuscritos completos como para la edición.

Propongo, por lo tanto, la siguiente solución, que modifica el stemma codicum de la estudiosa italiana:

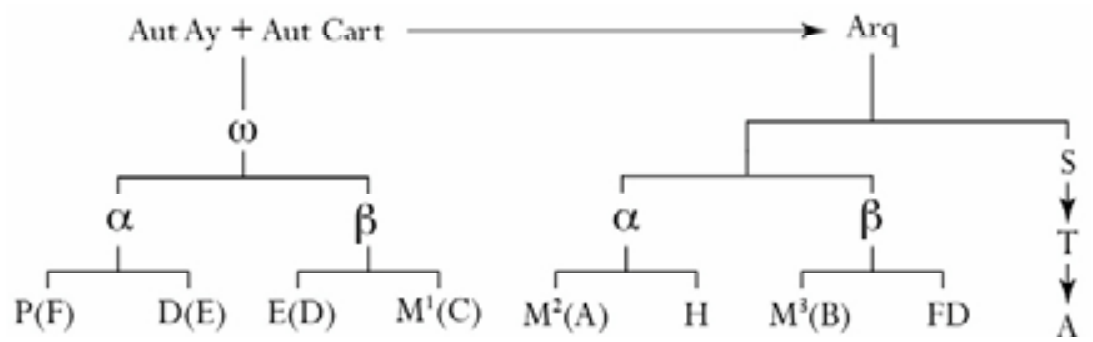

Existe un arquetipo (Arq), que es el producto de la unión del autógrafo de Ayala (Aut Ay) y del autógrafo del texto Cartagena (Aut Cart), del cual derivan los manuscritos completos (divididos en a y b) y las ediciones. Los otros manuscritos incompletos derivan del arquetipo $\mathbf{w}$, que deriva $-\mathrm{a}$ su vez- de Aut Ay.

La otra posibilidad es que los encargados de la edición sevillana (Meynardo Ungut y Lançalao Polono, o las personas que tuvieron a su cargo la revisión) hayan querido "mejorar" el texto que estaban transcribiendo. Éste, además, tiende a ser simplificado.

Scoma (que deriva de $\omega$, un arquetipo común) y Cay tienen en común una serie de lagunas, que testimonian que ambos textos tuvieron origen en 
un antígrafo común, que podría ser incluso el autógrafo de Pero López de Ayala. Llama solo la atención de que en ambos textos falta la traducción de IX XV. Gementes aliqui, que sí estaba presente en la Redacción A; no así el ya citado IX XVII 6.

\section{COMPARACIÓN ENTRE LA TRADICIÓN MANUSCRITA Y EL TEXTO DE LA EDICIÓN}

En el texto impreso, además de la ARENGA hay un PROLOGO, que es la traducción de la DEDICATORIAA MAINARDO DE' CAVALCANTI. Esta última se encuentra solo en dos de los manuscritos examinados por Isabella Scoma $\left(\mathrm{CsM}^{2}\right.$ y $\left.\mathrm{CsM}^{1}\right)$. En cuanto al Índice, suele ser más extenso que el texto que encabeza cada capítulo. Además, en varias ocasiones, el Índice se refiere al "auctor", mientras que el título se refiere a "doctor".

Anota Hortis, refiriéndose a la edición de Alcalá 1552, de la cual tenía un ejemplar y que también había visto en la Biblioteca Mazarina de París:

“Ho già notato (p. 608 e 609 delle O.L.) che nell'edizioni della versione spagnuola, l'opera del Boccaccio, che ha soltanto nove libri, è partita erróneamente in dieci, col dividere in due parti il libro IX. Il decimo libro comincia in questa edizione al verso del $\mathrm{f}$. CXXX con la storia della papessa: Libro decimo dela cayda de Principes del Papa Juan, que siendo mujer fingio ser / hombres y alcanço a ser Papa. / Capitulo primero /. - Ho pure notato che in questa stampa mancano parecchi capitoli dell'opera boccacesca. Queste cedizione contiene la versione spagnuola di Don Pedro Lopez de Ayala, e di Don Alonso Garcia, che fu poi vescovo di Burgos e cardinale. Don Juan Alfonso de Zamora narra nel sopraccitato Prologo y Arenga come questa versione fu fatta, e fino dove giunse il d'Ayala. "El dicho señor Pero Lopez (scrive Juan Alfonso) romanço los ocho [cioè i primi 8 libri]: hasta la meytad del capitulo que habla del rey artus de Inglaterra, que es dicha la gran Bretaña: y de Morderete su hijo, y dende en adelante romanço el dicho dean, el diciendo, \& yo escriuiendo". - Si badi che il passo seguente della lettera a Mainardo: "Hispani semibarbari et efferati homines" è parafrasato così: "en algún 
tiempo los de ciertas comarcas del mundo fueron tenidos poco menos que bestias: y llamados barbaros"27.

He elaborado un cuadro comparativo del Índice, tanto de Cs como de Cay, incluyendo la correspondencia de los textos de los capítulos, pero desgraciadamente no puedo incluirlo por su extensión. Sin embargo, puedo evidenciar que la diferencia más importante es la estructura en capítulos del volumen, puesto que todos los manuscritos -incluso los incompletos- están divididos en nueve libros, que corresponde a la división de Boccaccio. Sin embargo, las ediciones están divididas en diez libros y el inicio del Noveno coincide con el capítulo que Ayala dejó incompleto.

\section{¿Cómo se explica esto?}

Mi hipótesis es la siguiente: los encargados de la edición no tenían a mano un texto en lengua original y armaron el volumen siguiendo la distribución de Zamora (que, en la Arenga, indica que los libros eran diez). O, tal vez, decidieron iniciar un nuevo Libro con los capítulos traducidos por Cartagena. $\mathrm{Y}$, al ver que excedían la cantidad de los capítulos de los otros Libros, lo dividieron en dos dando origen a los Libros IX y X.

De los manuscritos que han llegado hasta nosotros, solo uno está fechado: el $C s F D$, que fue concluido en Brujas el 30 de diciembre de 1470, esto es 54 años después de que Zamora terminó su edición (1422) y 25 años antes de que se publicara (1495). Dos de los incompletos (CsM ${ }^{1}$ - Scoma C; $C s E$ - Scoma D) terminan donde acaba el texto de Ayala; $C s H$ tiene una laguna precisamente allí; dos llegan casi hasta el final ( $\mathrm{Cs} O$ - Scoma E; $C s P$ - Scoma F); y $C s W$ es desechable por ser del siglo XVII.

El códice $C s M$ es una copia declarada de la edición $C s A$ y $C s G$ también parece serlo de una de las ediciones. Cabe preguntarse, por lo tanto, si alguno de los restantes manuscritos lo sea.

En lo que respecta a los revisados por Isabella Scoma, la respuesta es rotundamente negativa: los textos Scoma y Cay expresan las mismas ideas, pero con palabras distintas, como si fueran dos traducciones diversas de un mismo texto original.

Propuse un stemma codicum en la Sección 7 y adelanté que pudo haber una manipulación por parte de los impresores. Ahora paso a comparar ambos textos, como fundamento de lo que ya he planteado. 


\section{1. Éstas son las LAGUNAS de ambos textos:}

Faltan los textos siguientes: la frase final de I Xvi 10 [Paupertati applaudet: Est equidem; et ideo in ipsius infortuniuim veniendum, est. N.B.- Los párrafos I XVI 9-10 forman parte del comienzo del Cap. XVII del Libro I (Scoma/Cay); luego sigue: I XVII 1-19]; I XVIII 19-34 [In mulieres; el texto se interrumpe en el párrafo 18 y es reemplazado por un texto apócrifo]; II XIX [Miseri quídam]; II x 22-31 [De Didone Regina Cartaginensium; como señala justamente Zaccaria, en el texto de Boccaccio no hay mención alguna a Eneas, ya que su fuente son los Epitoma historiarum Philippicarum Pompei Trogi, de Marcus Iuniani Iustini (Justino). Fuera de una breve referencia en el De mulierubus claris (XL 14), en la Genealogia deorum gentilium (XIV 13 - 721, 26) anota: "Composuit fabulam in multis similem Dydonis historie" ${ }^{28}$. Se trata, por lo tanto de una intervención del traductor]; II XI 2-3 [XI. In laudem Didonis]; II XVIII 8: XVIII [Pauca de somniis]; III v 2-9 [V. Gemebundi quídam; el traductor estructuró un CAPÍTULO VI. DE XERÇES REY DE PERSIA, que está constituido de la manera siguiente: (III v 1) (III v 2-9) - (III vI 1) - (III vI 25); Scoma/ Cay: (III v 1) - (III vI 1) - (III vi 25)]; IV VIII 13 [VIII. De Alexandro Epyrotarum rege; el texto falta en los dos casos, pero la traducción es distinta]; V IV 22 [IV. In cives hominisque nequam; es el párrafo final; no está ni en Scoma ni en Cay. Además, se presentan otras variantes de este tipo: V IV 21: sub manibus ligone aratroque in callum duratis et sub ex grege domestico sumptis laciniis latuisse animam tanta virtute conspicuam et splendores eorum fictos vera meritorum luce turbantem...; Scoma: so el aradro las manos enduresçidas con callos e so una pobre vida, él e su mujer e sus fijos, con poco pan e leche mantenidos, estar un coraçon tan fuerte e tan virtuoso (p. 280, 109-111); Cay: sobre el arado et las manos enduresçidas con callos: $y$ el y su mujer et fijos con poco pan et leche mantenidos: alcanço vna corona tan excelente por tener el coraçon tan noble e tan fuerte et virtuoso (f. lxxx $\mathrm{r}^{\mathrm{o}} \mathrm{a}-\mathrm{b}$ ). La similitud entre ambos textos es tan evidente que creo que es una prueba más de un antígrafo común, en el que el traductor leyó mal y confundió laciniis (de lacinia $=$ borde) y latuisse $($ de lateo $=$ esconder) con un derivado de lactus (= leche)]; V v 3-5 [V. Grandis infelicium turba]; V vi 2-5: VI. De Syphace rege Numidie; faltan otros textos en el capítulo, pero basta con este ejemplo para darse cuenta de que las traducciones son diversas]; V XI 9 [XI. De Prusia Bithinie rege; es el párrafo final]; V XIII 5 [XIII. De more Fortune et 
deiectis paucis; es el párrafo final]; falta $\mathrm{V}$ XVIII 9-10; en estos dos párrafos que faltan, Boccaccio exhorta a los hombres a no ser soberbios]; VI 20-37 [I. Collocutio Fortune et auctoris et quorundam infelicium demonstratio]; VI VII 4 [VI. De Horode rege Parthorum]; VI VIII 3-5 [VIII. Adventus flentium; faltan las desventuras de Postumio Albino, lugarteniente de Sila, de Fabio Adriano y de Sotimo, rey de los Tracios]; VI XI 6-15 [XI. Ingens caterva dolentium; faltan las líneas en que diez personajes de la Antigüedad lloran sus desgracias, acusando a la Fortuna]; VII i 1-10 [ I. Et primo quorundam infelicium concursus describitur; falta el capítulo completo]; VII III 8-55 [III. Tristes quídam et Tyberii Cesaris ate Gai Caligule iurgium cum Valeria Messalina; el texto llega hasta VII III 6: Seu potius soporiferas herbas papavera opiumve et medicata vina ut occupantem libidines tuas Claudium non alto somno demersum, sed fere exanimem redderes?]; VII v 1-5 [V. Afflicti quídam; falta el capítulo completo];VIII II 1-13: II. Imperatores miseri plures; falta el capítulo completo]; VIII Iv 14-25 [IV. In Saporem Persarum regem et Valerianum Romanorum imperatorem; el texto llega hasta VIII IV 13: Nil enim interest inter preterite decoris immemorem et delecte atque extreme sortis hominem]; VIII x 1-11 [V. Caterva Cesarum deiectorum; falta el capítulo completo]; VIII XIII 1-7 [XVIII. Dolentes plurimi falta el capítulo completo]; VIII Xv 1-9: XVIII. Dolentium descriptio brevis; falta el capítulo completo]; VIII XVIII 1-7 [XVIII. Deiecti quídam; falta el capítulo completo]; IX Xv 1-4 [XV. Gementes aliqui; falta el capítulo completo]; IX XXVII 6 [XVIII. Pauci flentes et libri conclusio].

Por su importancia, cito aparte el caso de VIII i 14-31, comparando el texto de Scoma y de Cay (que llega hasta VIII i 13: et stilo commendata perenni) con Cas. En la primera columna coloco el texto A y entre paréntesis los agregados del texto B. La comparación con el texto traducido deja en claro que está incompleto. Ya en el texto A faltaban los párrafos 13-17. El resto del capítulo - del que transcribo solo aquellas partes que no tienen variantes- no se tradujo, porque faltaba en el original que López de Ayala tenía a la vista o porque lo consideró poco relevante. 
VIII. I. Et primo viri clarissimi Francisci Petrarce in auctorem obiurgatio

\begin{tabular}{|c|c|c|}
\hline Cs (Ricci-Zaccaria) & Edición Scoma & $\begin{array}{l}\text { Cay (Pérez deAyala- } \\
\text { Zamora) } \\
\end{array}$ \\
\hline $\begin{array}{l}\text { 1-11. Quid inquam? } \\
\text { Satis animadversum } \\
\text { est quietem corporis } \\
\text { nimiam torporis matrem } \\
\text { et ingenii hostem fore... } \\
\text { Hec brevissimum } \\
\text { mortalis vite tempus facit } \\
\text { amplissimum et, quasi } \\
\text { vita alia, defunctorum } \\
\text { posteritati meritos } \\
\text { testatur honores. Hec, } \\
\text { cum vitali robore predita } \\
\text { agat ex morte triunphum, } \\
\text { a solis longissimis } \\
\text { seculorum spatiis, cum } \\
\text { nil mortales habeamus } \\
\text { eternum, sensim minuitur } \\
\text { nec absque temporis, } \\
\text { cuncta rodentis, labore } \\
\text { longevo consumitur, cum } \\
\text { a continuo fere viventium } \\
\text { nutriatur relatu. }\end{array}$ & $\begin{array}{l}\text { Pues, ¿qué dirá? Asaz } \\
\text { manifiesta cosa es que la } \\
\text { mucha folgança es madre } \\
\text { de la pereza e ocçio e } \\
\text { enemiga muy grande del } \\
\text { yngenio... La fama este } \\
\text { tienpo breve desta vida } \\
\text { mortal faze ser aún muy } \\
\text { más largo e ansí, como en } \\
\text { otra vida, da testimonio } \\
\text { de los que bien fizieron, } \\
\text { porque sienpre quede } \\
\text { dellos remenbrança e } \\
\text { honrrada memoria, }\end{array}$ & $\begin{array}{l}\text { Pues asaz manifiesta } \\
\text { cosa es que la mucha } \\
\text { folgança et ocio es madre } \\
\text { dela pereza et grande } \\
\text { enemiga del yngenio... } \\
\text { este breue tiempo que } \\
\text { passaron en esta vida } \\
\text { mortal. E mayormente } \\
\text { ser muy mas mejor } \\
\text { et mas gloriosa fama } \\
\text { perpetua enla otra vida } \\
\text { en testimonio delos } \\
\text { que virtuosamente } \\
\text { obraron et fizieron aca: } \\
\text { por que siempre quede } \\
\text { dellos remembrança } \\
\text { et onrrada memoria. }\end{array}$ \\
\hline $\begin{array}{l}12 \text { - Cuius rei } \\
\text { evidentissimum } \\
\text { argumentum est quod } \\
\text { suo robore literis infixo: } \\
\text { Ninum vetustissimum } \\
\text { Assyriorum regem cuius, } \\
\text { nedum alia, sed huius } \\
\text { opere stante nomine cinis } \\
\text { deletus est; Abraham } \\
\text { israelitici populi patrem, } \\
\text { Moysen [fugientium } \\
\text { ducem, Homerum vatem } \\
\text { precipuum,] Aristotilem } \\
\text { [Peripateticorum } \\
\text { principem,] Virgilium, } \\
\text { [no está en B] } \\
\text { Affricanum }\end{array}$ & $\begin{array}{l}\text { e déstos tales argumentos } \\
\text { e pruevas muy } \\
\text { manifiestas tenemos. } \\
\text { Bien sabemos que aquel } \\
\text { muy antiguo Nino, rey } \\
\text { de Siria, que solamente } \\
\text { las escrituras son las } \\
\text { que guardan oy la su } \\
\text { fama; eso mesmo digo } \\
\text { que aquel Abraham, } \\
\text { padre de aquel pueblo } \\
\text { de Ysrael; de Moysén, } \\
\text { aquél que guiava el } \\
\text { pueblo quando fuyó de } \\
\text { Egipto; otrosí Omero, } \\
\text { aquel poeta muy grande; } \\
\text { Aristótiles, prínçipe de }\end{array}$ & $\begin{array}{l}\text { y estos tales argumentos } \\
\text { et prueuas muy } \\
\text { manifiestos los veemos et } \\
\text { tenemos. Ca a vn aquel } \\
\text { antiguo Minos rey de } \\
\text { syria avn que gentil: por } \\
\text { las obras virtuosas que } \\
\text { fizo: oy es guardada su } \\
\text { fama. Et otrosy digo de } \\
\text { aquel padre de todo el } \\
\text { pueblo de ysrael Abraam } \\
\text { et Moysen que guio todo } \\
\text { el pueblo quando fuyo de } \\
\text { egipto Eotrosy Homero } \\
\text { aquel poeta tan grande } \\
\text { et Aristotiles principe } \\
\text { delos philophos. Cipion }\end{array}$ \\
\hline
\end{tabular}




\begin{tabular}{|c|c|c|}
\hline $\begin{array}{l}\text { bellicosissimum, } \\
\text { honestissimos] Catones } \\
\text { aliosque [insignes } \\
\text { viros, quos quasi } \\
\text { perenni viriditate ipsa } \\
\text { in hodiernum usque } \\
\text { deduxit perpetuos. } \\
\text { Quos, es agente, } \\
\text { noscimus laudamus et } \\
\text { colimus magnamque } \\
\text { animi voluptatem } \\
\text { sentimus, dum id quod } \\
\text { illi suscipiunt a nobis, } \\
\text { nos labore nostro apud } \\
\text { futuros posse suscipere } \\
\text { credimus; et sic futuram } \\
\text { gloriam spirantes } \\
\text { anticipamus. Quod si } \\
\text { quis parum apud mortales } \\
\text { existimet, sui profecto] } \\
\text { non satis est compos. }\end{array}$ & \begin{tabular}{|l} 
los filósofos; Çipión el \\
Africano, cabdillo muy \\
famado, e otrsý muy \\
muchos nobles omes, los \\
quales ansí como con una \\
perdurable ventura fasta \\
el día de oy su fama los \\
mantiene. Sy de algunos \\
de los mortales dizen \\
que esto poca cosa es, \\
por çierto dizen lo que \\
les plaze e a su voluntad, \\
más perdónenme que \\
otra es la verdad.
\end{tabular} & $\begin{array}{l}\text { el africano caudillo muy } \\
\text { famoso y efforçado. E } \\
\text { de otros muy nobles } \\
\text { efforçados que aqui non } \\
\text { nombro: los quales assy } \\
\text { como vna perdurable } \\
\text { verdura [sic] fasta el } \\
\text { dia de oy su loor et muy } \\
\text { grand fama los mantiene. } \\
\text { E sy alguno delos } \\
\text { honbres mortales dize: } \\
\text { que esto es poca cosa } \\
\text { por cierto dizen lo que } \\
\text { les plaze et fablan a su } \\
\text { voluntad: mas perdonen } \\
\text { me que otra es la verdad. }\end{array}$ \\
\hline $\begin{array}{l}\text { 13. Falta en la } \\
\text { Redacción A. [Credo } \\
\text { ego, quantumcunque } \\
\text { maiores nostri, Ieronimus } \\
\text { et Augustinus et alii } \\
\text { sanctitate conspicui } \\
\text { homines, etsi desiderio } \\
\text { eterne glorie in labores } \\
\text { ultro irent egregios, } \\
\text { etiam tracti sunt fame } \\
\text { temporalis appetentia, } \\
\text { cum insideat omnibus a } \\
\text { natura stimulus quidam } \\
\text { qui nocte dieque per } \\
\text { virtutem ad fulgorem } \\
\text { hunc nos concitet et } \\
\text { inpellat. Qui, dum } \\
\text { etiam si velimus, } \\
\text { exinaniri non potest. } \\
\text { Hinc non ad decorem } \\
\text { tantum divinorum }\end{array}$ & $\begin{array}{l}\text { Yo bien creo, e non } \\
\text { dubdo quanto quier } \\
\text { que fueron santos e } \\
\text { mayores Sant Ierónimo } \\
\text { e Sant Agostín e otros } \\
\text { muy grandes santos } \\
\text { letrados, que si por deseo } \\
\text { de la vida perdurable } \\
\text { en fazer algunas obras } \\
\text { santas trabajaron, } \\
\text { enpero naturalmente, } \\
\text { como a todos los omnes } \\
\text { alcançan, algunt aguijón } \\
\text { natural de la fama } \\
\text { tenporal los acuçió. E } \\
\text { sy queremos del todo } \\
\text { non ser tocados desta } \\
\text { naturaleza, non puede ser } \\
\text { que non tan solamente } \\
\text { para apostamiento de } \\
\text { las obras divinales esto }\end{array}$ & $\begin{array}{l}\text { E yo bien creo et non } \\
\text { dubdo: que quantos } \\
\text { fueron sanctos et } \\
\text { mayores sant Iheronimo } \\
\text { et sant Agostin et ottros } \\
\text { muy sanctos hombres } \\
\text { letrados: los quales } \\
\text { por deseo dela vida } \\
\text { perdurable algunas } \\
\text { cosas trabajaron anssy } \\
\text { como por fazer obras } \\
\text { virtuosas et sanctas. } \\
\text { Empero naturalmente } \\
\text { como a todos los omes } \\
\text { alcance algund aguijon } \\
\text { natural dela fama } \\
\text { temporal los acucio. E } \\
\text { sy del todo no queremos } \\
\text { ser tocados desta } \\
\text { naturaleza: no puede ser } \\
\text { que para apostamiento }\end{array}$ \\
\hline
\end{tabular}




\begin{tabular}{|c|c|c|}
\hline $\begin{array}{l}\text { operum, que nostro } \\
\text { non indigent lumine, } \\
\text { sed ad perpetuationem } \\
\text { sui nominis apud } \\
\text { posteros verborum } \\
\text { a talibus maiestas } \\
\text { quesita est et stilo } \\
\text { commendata perenni.] }\end{array}$ & $\begin{array}{l}\text { se faze - las quales non } \\
\text { han menester del nuestro } \\
\text { estudio nin del nuestro } \\
\text { alunbramiento - mas para } \\
\text { perpetuar nonbres de los } \\
\text { que trabajan, para que } \\
\text { finquen las sus obras en } \\
\text { alunbramiento de los } \\
\text { que después vinieron } \\
\text { fue esto fallado. Pues } \\
\text { no es ansý del todo nin } \\
\text { cunple menospresçiar la } \\
\text { fama nin deve ser tenida } \\
\text { como cosa por demás } \\
\text { e vana, mas por lode } \\
\text { de Dios es de buscarla } \\
\text { con quantas fueças } \\
\text { e trabajos pudieren } \\
\text { ser, porque en quanto } \\
\text { faziendo buenas obras } \\
\text { te esforçaras de ganar } \\
\text { buena fama e alargar } \\
\text { la gloria del tu nonbre, } \\
\text { conoscas que Dios es } \\
\text { aquél que todo esto } \\
\text { faze y puede alargarlo } \\
\text { e non otro ninguno. }\end{array}$ & $\begin{array}{l}\text { destas cosas naturales } \\
\text { esto se faze: las quales } \\
\text { no han menester de } \\
\text { nuestro estudio algun } \\
\text { alunbramiento: mas para } \\
\text { perpetuar los nonbres } \\
\text { delos que trabajan: por } \\
\text { que queden sus obras en } \\
\text { luz et lumbre delos que } \\
\text { despues vinieren: et por } \\
\text { esso fue esto fablado E } \\
\text { pues assy tan manifiesto } \\
\text { es a nos del todo non } \\
\text { cumple menospreciar la } \\
\text { fama: ni deue ser auida: } \\
\text { como cosa por demas / } \\
\text { o vana: mas por amor } \\
\text { de dios: es de buscar } \\
\text { la por quantas fuerças } \\
\text { et trabajos pudiere ser } \\
\text { hauida: por que en } \\
\text { quanto faziendo buenas } \\
\text { obras te esfuerces de } \\
\text { ganar buena fama: } \\
\text { et conociendo a dios } \\
\text { alegren la gloria de } \\
\text { tu nombre: el qual te } \\
\text { de gracia al cumplir } \\
\text { tu deseo:ca enel es y } \\
\text { en otro alguno non: } \\
\text { porque con su ayuda } \\
\text { el sea agradable enla } \\
\text { obra por ty començaba } \\
\text { et des della buena fyn. }\end{array}$ \\
\hline $\begin{array}{l}14-17 . \text { Faltan en } \\
\text { la Redacción A }\end{array}$ & FALTAN. & FALTAN. \\
\hline $\begin{array}{l}18-31 . \text { Non ergo } \\
\text { negligenda est, [non } \\
\text { ocio calcanda, non } \\
\text { tanquam inane et } \\
\text { superfluum detestanda, } \\
\text { sed propter Deum totis }\end{array}$ & FALTAN. & FALTAN. \\
\hline
\end{tabular}




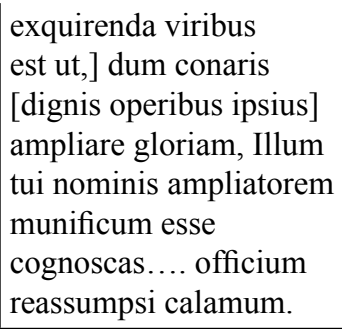

Sobre el texto traducido, identifico de inmediato, en VIII I 2, una periblepsis por homeoteleuton:

Scoma: pues que ninguno non te aquexa a lo fazer, e esfuerças de buscar e pesquerir la fama de los antigos desaventurados e ponerlo por escripto con nuevas letras, non deseas prolongar el tu nonbre nin tus dias.

Cay: Pues ninguno non te aquexa alo fazer: et pues assy es: esfuerça te de buscar et pesquisar la fama de los antiguos: que nynguno non te contraría para esta ora que has començado a fazer et de poner por escriptura. E porende cata bien: et mira la fama delos antiguos que fueron desauenturados: et ponla por escripto por nueuas letras: et no cobdicies prolongar el tu nombre ny los tus dias.

Como está en Scoma y no en Cay, me parece que es una prueba suficiente para sostener que el arquetipo $\omega$ de los masnuscritos proviene de un antígrafo común a Cay.

El traductor no entiende los textos siguientes:

- VIII i 9: non nisi per virtutem acquiritur.

Cay: nunca se cobra ninguna saluo por verdad,

Scoma: nunca se cobra nin se gana salvo por virtud.

- VIII I 10: bene meritorum nomina in fines usque terre tollit in lucem

Scoma: ansí como por una carrera pública con grant alegría las lieva a los çielos

Cay: asy como por una carrera publica los angeles las lieuan alos cielos:

En todo caso, en el par. 12, acoge los agregados de B.

- También al revés VIII i 3:

Scoma: ¡O cobdiçia tan sin bien e con tan poco entendimiento! Ca verná ora - e ya es - la qual te llevará e te apartará de todas estas cosas mortales entre las quales estás enbuelto, la qual quebranta el tu cuerpo, la qual tornará todos sus fechos como en una fablilla. Ruégote que me digas: ¿qué puedes tú llevar de todas estas cosas pasaderas desta breve e mezquina vida, aunque todo el mundo a boca llena otra cosa non diga nin cate nin alabe salvo el tu nonbre? 
$\mathrm{Ca}$ en la ora que peresçiere ese tu rostro por el qual tú eres conosçido, todas las cosas pasaderas deste mundo, que a ty eran llegadas, peresçerán.

Cay: O cobdicia tan syn bien tan poco entendida: que verna hora: et ya es la qual te apartara de todas estas cosas mortales entre las quales tu agora estas embuelto: et quebrantado el cuerpo et tomados tus fechos en una fablilla. $€$ Pues digo te agora que me digas: que puedes leuar de aquestas cosas passaderas deste mundo que a ti eran llegadas pereceran.

8.2. Hay también, en común, evidentes ERRORES DEL TRADUCTOR:

- I v 9: nec non Pandionis, Phylomena perdita, miseranda senectus; et Therei nephanda libido (y la vejez miseranda de Pandione, después de la pérdida de Philomena, la nefanda líbido de Tereo)

Scoma: otrosý la piadosa vejez de Philomena e la luxuria envergonçada de Thereo (p. 23, 116-117)

Cay: E otrosí la piadosa vejez de philomena. et la lujuria envergonçada de Teseo (f. vj v b)

Como señala Scoma, la equivocada atribución de la vejez de Philomena se debe a un error del traductor o al hecho de que Pandionis no estaba en el texto latino. Pero el Teseo de Cay es, sin duda, un error del editor.

- IX r 22: Et veneno perimitur et filii gladio extinguntur (cuando habla de la muerte de Teodorico)

Scoma: fue muerto con poçoña e con cuchillo de su fijo (p. 468, 125-126)

Cay: fue muerto con ponçoña et con cuchillo de su hijo (f. cxxxij v ${ }^{\circ}$ b)

El error de traducción ("y los hijos fueron muertos a cuchillo") es común a ambos textos.

\subsection{Existe también una gran cantidad de CAMBIOS DEL TRADUCTOR} (o, probablemente, del EDITOR, si se trata del texto impreso). Cito solo uno de ellos:

- II vII 9 - De Athalia regina Ierusalem: Ioas, solus Ochozie regis filius, in cunabulis una cum nutrice, merito Iosabe sororis Ochozie, in domum Ioadam pontificis viri sui clam deportatus neci sublatus est.

Scoma: Joas, solo fijo del rey Ocozías, que avía fincado niño en la cuna con la su ama que lo criava, escondidamente fue levado a casa de Josabé, el obispo, porque lo non matasen (p. 90, 59-62) 
Cay: joas fijo del rey ocozias que auia quedado niño enla cuna con vna su ama que lo criaua: escondidamente lo lleuaron a casa del obispo josade: porque lo no mandasse matar la reyna athalia (f. xxvij $\mathrm{r}^{\mathrm{o}}$ a)

\subsection{En muchísimos casos, más que de cambios, se trata de AGREGADOS DEL TRADUCTOR (o del EDITOR, en el caso del texto impreso):}

Por ejemplo, en la historia de Sansón (I XVII 4) hay una referencia al enigma que éste planteó después de encontrar la miel en el cráneo del león. He aquí los dos textos:

A: Tandem illud idem iter dum faceret, et in ore crene oppresse a se nuper belue mellis favum forte repperisset et comedisset, cognatis ex coniuge, appositis solventi muneribus, problema proposuit inenodabile fere, cuius occultum cum aperuisset blanditiis coniugis, advertit solutum esse. Ob quod meritum

B: Tandem illud idem iter dum faceret, et in ore crene oppresse a se nuper belue mellis favum forte repperisset et comedisset, cognatis ex coniuge, appositis solvent muneribus, problema proposuit inenodabile fere, cuius occultum cum aperuisset blanditiis coniugis, advertit liquido eius opere illud ab affinibus solutum esse. Ob quod meritum

Boccaccio señala que "después a los parientes por parte de la esposa propuso un problema casi insoluble, prometiendo un premio a quien lo resolviese; pero, habiendo revelado la secreta solución ante los halagos de la cónyuge, se dio cuenta ciertamente de que, gracias ella, el problema había sido resuelto por los parientes".

Sin embargo, en los manuscritos el sentido es completamente diverso:

Scoma: Finalmente en quanto Sansón tornase por aquel camino que dezimos e en la garganta del león que matara fallase una colmena de abejas que allý fazían su miel, comió della. Los sus cuñados, ya con envidia e con consejo de la su mujer, le pusieron e demandaron una questión muy grave de responder; enpero, quando él gela declaró con falagos e lisonjas de su mujer entendió que por consejo de su mujer era fecho e que los sus cuñados con envidia lo fazian. E por esta razón (p. $64,25-32)$

Y en Cay, se agrega una serie de datos aclaratorios:

Cay: E finalmente quando Sanson torno por este camino fallo en la garganta del león que matara vna enxambre de miel con sus auejas et 
comio dellas: et lleuo tres panales con otros dones que truxo a su mujer. $\mathrm{Y}$ un dia en un convite con mucho placer et solaz a treinta omnes que en ende enel convite estauan: les puso vna question. La qual si les declarasen en siete días les prometía a cada vno su vestidura o sino que otras tantas le diesen ael quanto ellos heran. La qual question propuso desta manera. Del que come salio manger: el del fuerte salio fortaleza. La qual como ellos no sopiessen declarar: rogaron a su mujer con muchos dones que le dieron que supiesse del la declaración della. Por quanto ellos la fallauan ser muy graue de responder: et con lisonjas et falagos de su mujer el gela declaro: E como los cuñados lo quisiesen mal con embidia: et la mujer de la intención delos hermanos: por esta razón (f. $\left.x x r^{0} a-b\right)$

Es Sansón el que propone la cuestión y, además, la expone con palabras. Además, los convidados son treinta y los días para resolverlo son siete. La información completa viene de Liber Judicum 14, 10-18. Pero hay otra que proviene de las Antiquitates iudaicae de Flavius Josephus, en la traducción de Rufino Aquileiese (V viii 6), que Boccaccio leyó y copió en el actual Cod. Laurenziano LXVI 1. Ésta es: los enjambres de miel son tres. Pero -¡atención!- los parientes no convencieron a la mujer con "muchos dones que le dieron", sino con la amenaza de pegarle fuego junto con la casa de su padre. El autor del texto Scoma, obviamente, no entendía lo que estaba traduciendo. Me da la impresión de que el editor de Cay trata de "mejorar" el texto para hacerlo más inteligible.

El capítulo De Nero Claudio Cesare (VII IV), que constituye el VIII III del texto Scoma (pp. 393-399) y el capítulo iij del Libro Seteno de Cay, tiene tal cantidad de variantes que no me parece el caso de transcribirlo.

Señalo solo las variantes anotadas por Isabella Scoma: p. 393, 3-4; p. $394,57-58,65$; p. 396, 113-115, 117, 117-118, 123-124; 143; p. 397, 149, $151,159-160,167-168,174-175,184$; p. 398, 199-200, 220; p. 399, 243244, 264-266.

Pero agrego la siguiente, que está presente solo en Cay. Es una intervención del editor y tiene un claro sabor chauvinista:

- VII IV 5: et Anneo Senece clarissimo viro atque apprime erudito commendatus.

Scoma: E fue luego Nero encomendado que lo toviese como su maestro aquel muy famoso varón e sabidor Séneca. E después (p. 394, 28-30)

Cay: e assu fue luego nero encomendado que lo touiesse como su maestro aquel famoso maestro et sabio entendido Seneca enla cibdad de cordoua nascido. E despues (f. cxii $\mathrm{v}^{\mathrm{o}} \mathrm{b}$ ). 
8.5. Una situación diferente se da cuando falta un texto y es reemplazado por un COMPENDIO, que es obra del traductor. Cito dos ejemplos:

\section{- Falta VII VII 5-13: VII. In gulam et gulosos.}

El texto llega hasta fines de VII VII $4:$... et quot corpori egritudines anxie ingerantur.

De allí para adelante, el texto VII vii 5-13 [Attamen uti cuncta nec enumerare mens est ... Quam dum sperneret, Aulus invenit celso residens solio contemptores nec etiam illi saturitas frontis dedecus aut corporis abstulit cruciatus] se compendia de la manera siguiente:

Scoma: Enpero asý como non cunple de lo contar todo por especial, así sería bien de lo todo callar, ca muchos de los tales manjares, asentado en aquellas solepnes mesas, no catan nin piensan nin ponen su diligencia en buscar aquello que abasta al mantenimiento de la natura, mas solamente a fechir aquella tragonía de los sus vientres. E por ende no puede omne callar que en alguna cosa de las tales non fable para las contar, e manifiesto es el mal que de lo tal sigue. Ca los ojos çiegan, la boca fiede, los mienvros trimen, paralizia creçe o la tísca se sigue, la suziedat de la sarna se renueva, el estómaco se enflaquece, e de aquí viene lo que los físicos dizen que más omes mata quel cuchillo (p. 408, 28-38).

Cay: Empero assy como no cunple delo contar del todo por especial: assy no seria bien del todo callar: que muchos de los tales manjares asentados en aquellas solemnes mesas non ponen su diligencia en buscar aquello: que abaste al mantenimiento dela natura: mas solamente a fenchir aquella glotonia de sus vientres E porende no puede hombre callar que en algunas cosas delas tales non fablen para las ver et catar de manifiesto: qur muy prouado parece el mal que dela demasiada glotonia se sigue: que los ojos ciega: et la boca fiede et los miembros tremen et perlesía se apareja et la tísica se sigue et la suziedad dela sarna se renueua y el estomago se enflaquesçe: et de semejantes cosas nasçe lo que alas vezes a los físicos leuantan que dizen / que ellos mas matan que los cuchillos (f. cxvij $\mathrm{r}^{\mathrm{0}} \mathrm{a}$ )

\section{- Falta VII vIII 24-28: VIII. De excidio Ierusalem.}

El texto llega hasta fines de VII viii 23: ... in Romanorum predam conversum est. De allí para adelante, el texto VII vii 24-28 [Deleta igitur urbe regia et Iohanne Giscalo capto et Symone ex tyramnis alio ... sua in superstitione durantes] se compendia de la manera siguiente:

Scoma: de los Romanos. E ansí destroyda la çibdat real de Iherusalem, e menguado e tornado en ninguna cosa el su regno, e toda la muchedumbre de los judíos derramada, enpero aún non del todo peresçieron las sus malas costumbres, ca aún biven. E ansý la su mezquina codiçión dellos 
bien fuerte examinado en todos los lugares sirven e en todos los lugares son aborresçidos, 'porfiosos, maltraídos, a todos sospechosos e todavía en la porfía endurescidos (p. 412-413, 147-154)

Cay: delos romanos. E assy fue destruyda et robada la cibdad de Jherusalem: et amenguada et tomada en ninguna cosa: et todo su reyno perdido et destruydo: syn reyno et príncipe desu geeracion et toda la muchedumbre delos judíos desterrada et derramada por todo el mundo: et avn con todos estos trabajos et males no perescieron del todo sus malos vsos et costumbres que oy dia enellos biuen. E sy su maluada et mezquina condicion fuere examinada en todos los lugares: syruen et son aborrescidos et a todos sospechosos porfiosos: et maldito / et mal traídos, y en su mala porfia endurecidos.

8.6. El campo de los TEXTOS APÓCRIFOS es vastísimo. Como ejemplificación, copio solo un párrafo de un el texto comparado de I VIII, sin señalar las variantes en cursiva, porque son demasiadas y dificultarían la lectura.

\begin{tabular}{|c|c|c|}
\hline Cs (Ricci-Zaccaria) & Edición Scoma & $\begin{array}{l}\text { Cay (Pérez deAyala- } \\
\text { Zamora) }\end{array}$ \\
\hline $\begin{array}{l}10 \text { - Qui, stupefactus } \\
\text { responso, tandem } \\
\text { devenit in Phocidem; } \\
\text { ibique orta inter } \\
\text { exteros civesque } \\
\text { seditione, dum Layus } \\
\text { summopere componere } \\
\text { curaret in certamen } \\
\text { ruentes immixtus } \\
\text { turbe et incognitus, } \\
\text { ab Edipo gladio } \\
\text { percussus occubuit. }\end{array}$ & $\begin{array}{l}\text { El qual muy espantado } \\
\text { de tal respuesta partio } \\
\text { de allí e finalmente } \\
\text { llegó al logar Feçide, } \\
\text { do le fuera dicho. E } \\
\text { quando allí fue, falló } \\
\text { una grant contienda que } \\
\text { aquel día se levantara } \\
\text { entre los çibdadanos } \\
\text { de aquel lugar, e el rey } \\
\text { Layo salió allá por los } \\
\text { departir e asosegar e } \\
\text { bolviéndose entre las } \\
\text { conpañas que peleavan, } \\
\text { non lo conosçiendo, } \\
\text { EDipo que allí era } \\
\text { venido e andava en } \\
\text { aquella buelta firióle } \\
\text { de un cuchillo }\end{array}$ & $\begin{array}{l}\text { El qual de tal respuesta } \\
\text { muy marauillado: y } \\
\text { espantado con grand } \\
\text { cuydado partio de alli } \\
\text { et finalmente llego al } \\
\text { lugar de Fecide donde } \\
\text { le fuera dicho que } \\
\text { fallaria a su padre. et } \\
\text { como assy llego fallo } \\
\text { en aquel dia enla cibdad } \\
\text { muy grande contienda: } \\
\text { et van dos entre los } \\
\text { cibdadanos: Ca los } \\
\text { fallo todos metidos en } \\
\text { armas et peleando muy } \\
\text { cruelmente los vnos } \\
\text { con los otros. E en tal } \\
\text { manera se encendieron } \\
\text { enla pelea que al rey }\end{array}$ \\
\hline
\end{tabular}




\begin{tabular}{|l|l|}
\hline $\begin{array}{l}\text { al rey en manera } \\
\text { que murió luego. }\end{array}$ & $\begin{array}{l}\text { Layo su señor conuino } \\
\text { salir por los poner en } \\
\text { paz. et metiendose } \\
\text { entre las compañas } \\
\text { que peleauan non } \\
\text { conociendo Edipus que } \\
\text { allí era venido el rey } \\
\text { Layo ser su padre mas } \\
\text { metiéndose en aquella } \\
\text { vuelta como valiente } \\
\text { cauallero fauoreciendo } \\
\text { la parte del rey, el } \\
\text { qual atrauesando entre } \\
\text { vnos et otros por los } \\
\text { despartir: Edipus non } \\
\text { lo conosciendo de vn } \\
\text { golpe de espada lo firio } \\
\text { de tal guisa que el rey } \\
\text { Layo fue muerto. }\end{array}$ \\
\hline
\end{tabular}

La amplificatio es evidente. Todo el capítulo presenta un texto paralelo y - por lo tanto- existen tres versiones distintas que coinciden solo en algunos pasajes. Todo esto va más allá de las diferencias entre las dos redacciones que señalé más arriba.

En ambos textos castellanos hay errores comunes:

- I VIII 24: eam has miserias terminasse laqueo

Scoma: corrige Jocasta, pero en todos los manuscritos se lee: que todas estas llagas e dolores que Edipus pasó que a la fin con lazo puesto a su garganta los terminó e acabó (p. 33, 153-154)

Cay: que con quantas passiones et lagrimas Edipus passo: que finalmente en su postrimera voluntad: dispuso de morir. Et que con vn lazo ala garganta determino et acabo su desauenturada postrimeria (f. $\mathrm{xj}^{\mathrm{o}} \mathrm{a}$ )

- I VIII 26: ad solatium senectutis instantis, Creontis imperio catenis honustus in exilium pulsus est.

Scoma: olvidada la bienandança e solaz de la vejez que entonces le venía, en el señorío de Creontes, el enperador, cargado de cadenas e desterrado acabó sus días (p. 33-34, 161-163)

Cay: y el solaz et alegria dela vejez que entonce le venia con la gloria del reynar et consolacion delos fijos. Mas sobreuiniendo el señorio del 
emperador Creontes el rey edipus fue preso et cargado de cadenas. desterrado y enojado de beuir se esforço. Et acabo sus dias: (f. $x j \mathrm{r}^{\mathrm{o}}$ b)

Como anota Scoma, se entiende mal el texto latino, cuyo verdadero significado es "en alivio de la inminente vejez fue mandado al exilio cargado de cadenas por orden de Creonte".

Los conocimientos que tiene el redactor de Scoma son más amplios, pero los de Cay exceden la capacidad de un lector del siglo XIV. Boccaccio ya había tocado el tema en De Mulieribus Claris XXV y Genealogia Deorum Gentilium II, 68-74, sirviéndose de la Thebaidos de Estacio. En todo caso - a pesar de que está en Cas- no hay palabra alguna acerca de que Edipo hubiese sido unido en matrimonio a Jocasta por haber matado a la Esfinge o porque se creía que era hijo del rey Pólibo. Como señalan Ricci-Zaccaria, estas dos versiones están unificadas en Genealogia II 70, y la única fuente que se cita es Thebaidos I 66 y IV 376, a los que agregan dos de los Mythrographus Vaticanus, I 204 y II $230^{29}$.

- Ix 1-31: El capítulo sobre Teseo también es distinto en Scoma y en Cay, constituyendo textos paralelos, pero -al igual que muchos otros que figuran más adelante- no los citaré por exigencias de brevedad.

\section{CONCLUSIONES}

$1^{\mathrm{a}}$ - Los manuscritos completos que dan origen al texto Scoma provienen de un arquetipo, que incluye el texto traducido por Ayala, más el texto traducido por Cartagena: dicho presunto manuscrito lo denomino Arq. Ambos autógrafos (Aut Ay, que probablemente Juan Alfonso de Zamora tuvo en sus manos en 1442, y Aut Cart, que es la continuación firmada por Cartagena) hasta ahora figuran como dispersos.

$2^{\mathrm{a}}$ - Los manuscritos incompletos que figuran en el aparato crítico de la edición Scoma provienen de un arquetipo $\mathbb{\not}$, que proviene de Aut Ay.

$3^{\mathrm{a}}$ - El texto de Cay no proviene de los manuscritos que dieron origen al texto Scoma. Y se nota la intención del editor y/o los impresores de "mejorar" un texto paralelo. 
Para un texto de esta envergadura (más de 99.100 palabras) hay todavía bastante por analizar. Isabella Scoma adelantó muchísimo. Mi artículo ha intentado aportar nuevos antecedentes. Con nuestras fichas y resultados, tal vez otros estudiosos puedan llegar a pruebas más definitivas.

Mientras tanto, urge editar (necesariamente con criterio béderiano y debidamente anotado) el texto de las impresiones. Y, como puede apreciarse, es una tarea que ya he emprendido.

\section{REFERENCIAS BIBLIOGRÁFICAS}

Alvar Ezquerra, Carlos. 2001. Boccaccio en Castilla: entre recepción y traducción. Cuadernos de Filología Italiana $\mathrm{n}^{\circ}$ extraordinario: 333-350.

BlAnCo JimÉNEZ, José. 1977. Le opere di Giovanni Boccaccio in Spagna nel '400 e '500: una prima valutazione bibliografica. Miscellana Storica della Valdelsa 83: 36-53.

2013. ¿Qué es una edición diplomático-interpretativa? Literatura y lingüística 27: 311-344.

Boccaccio, Giovanni. 1495 (1999). Caída de prinçipes (Seville, 1495). New York: Hispanic Society. Ed. Eric Naylor. En Electronic Texts and Concordances of the Madison Corpus of Early Spanish Manuscripts and Printings, ed. John O'Neill, Madison-New York: HSMS, 1999 [CD-ROM].

1983. De casibus virorum illustrium, edición crítica de Ricci, Pier Giorgio y Zaccaria, Vittorio. Milano: Mondadori. Es el vol. IX de Tutte le opere di Giovanni Boccaccio y lo cito con la abreviatura Cas.

Hauvette, Henri. 1911 (2010). Recherches sur le "De Casibus virorum illustrium" de Boccace. En Henri Hauvette. Entre Camarades, Paris: Alcan. Reimpresión facsimilar de Whitefish (Montana, USA): Kessinger Publishing (2010).

1914. Boccace. Étude biographique et littéraire. Paris: Colin.

HoRTis, ATtilio. 1879. Studi sulle opere latine del Boccaccio con particolare riguardo alla storia della erudizione nel Medio Evo e alle letterature straniere, aggiuntavi la bibliografia delle edizioni. Trieste: Julius Dase.

Lucía Megía, José Manuel. 2001. Imágenes de recepción de Boccaccio a través de sus códices: primeras notas. Cuadernos de Filología Italiana ${ }^{\circ}$ extraordinario: 415-478.

Masai, Françors. 1950. Principes et conventions de l'édition diplomatique. Scriptorium 4: 177-193.

NAYLOR, Eric W. 1986. Pero López de Ayala's translation of Boccaccio's “De Casibus”. En John S. Miletich (publ.). Hispanic studies in honor of Alan D. Deyermond. A North American Tribute, pp. 205-215. Madison: Hispanic Seminary of Medieval Studies.

1992. Sobre la traducción de La caída de príncipes de don Pero López de Ayala. En Historias y ficciones. Coloquio sobre la literatura del siglo XV (29-31 octubre 1990), pp. 141-156. Valencia: Universitat de València.

1994. Text and concordance of Giovanni Boccaccio's De casibus virorum illustrium translated by don Pero López de Ayala, HSA, MS. B1196. Madison (Wis.): Hispanic Seminary of Medieval Studies. 
Petrucci, Armando. 1977. Edizione diplomatica o/e riproduzione? Un problema critico (con appendice boccacciana). Belfagor 32: 63-71.

Ricci, Pier Giorgio. 1962 (1985). Le due redazioni del "De Casibus". Rinascimento 12: 11-20. (Ahora en Studi sulla vita e le opere del Boccaccio. Ricciardi, Milano-Napoli: 179-188). Cito de esta última por ser más fácil de conseguir y consultar.

Scoma, Isabella. 1993. Pero López de Ayala.Caýda de príncipes. Messina: La Grafica Editoriale.

Torraca, Francesco. 1912. Per la biografia di Giovanni Boccaccio, Milano-Roma-Napoli: Dante Alighieri.

Zaccaria, Vittorio. 1977-78. Le due redazioni del "De casibus". Studi sul Boccaccio 10: 1-26. 1983. Introduzione. En Cas: XIII-LII; Nota al testo. En Cas: 875-904. 